\title{
¿Quiénes son ellos?: un estudio psicoanalítico sobre El proceso de Kafka
}

\section{Francisco Martins}

Instituto de Psicología, Universidad de Brasilia Brasilia, Brasil

El texto presenta el análisis y las reflexiones desarrollados en el Laboratorio de Psicopatología y Psicoanálisis de la Universidad de Brasilia, acerca de la cuestión de "él" ("ellos") en El proceso, de Franz Kafka, y en un caso de delirio de persecución. Fue especialmente investigado el estatuto del pronombre "él" en la paranoia. El trabajo muestra que la comprensión de "él" ("ellos") es un elemento esencial para la elucidación de la cuestión de la extrañeza en la psicosis y de la construcción de la actividad delirante. A lo largo del texto se señalan algunas cuestiones y articulaciones entre el análisis procedido, el psicoanálisis, la fenomenología y la comunicación lingüística, teniendo como hipótesis esencial que la psicosis consiste en la pérdida y reconstrucción narcisista de la función referencial del lenguaje.

delirio / lenguaje / referencia / psicosis / pronombres

\section{Who are they?}

This study presents analyses and reflections developed in the Laboratory of Psychopathology and Psychoanalysis of the University of Brasilia concerning the issue of "he" ("they") in The Process by Franz Kafka as well as in a case of persecutory delusion. The role of the pronoun "he" was especially investigated in the case of paranoia. The present work shows that the comprehension of "he" ("they") is a key element in the understanding of strangeness in psychosis and in the construction of delusional activity. Some issues and articulations about analysis, psychoanalysis, phenomenology and linguistic communication are addressed, having as an essential hypothesis that psychosis consists in the loss and narcisistic reconstruction of the referential's function of language.

delusion / language / reference / psychosis / pronouns

Traducción del portugués por Mercedes Quihillaborda Mourão.

Dirección del autor: fmartins@unb.br. 
Objets inanimés, avez-vous donc une âme?

Lamartine

Aprendemos con Freud que la extraña extrañeza (Das Unheimlich) es un fenómeno que no pertenece sólo a las variaciones anormales de la vida psíquica, pues está potencialmente presente en la vida cotidiana de todos nosotros. Está potencializada en todo análisis, ya que estamos siempre en este último caso, en terreno extraño, inusitado, desconocido, diferente de lo que nos es familiar. Ello ocurre siempre con algo que es exterior y extranjero en lo que se refiere a la experiencia consciente. Freud mostró que la extraña extrañeza trae consigo contenidos de orden familiar que, sin embargo, son relegados al inconsciente.

En el Laboratorio de Psicopatología y Psicoanálisis hemos trabajado en la perspectiva de que todo aquello que es anormal, patológico, alienado, extranjero puede enseñarnos acerca del tornarse humano. Es a partir de esta perspectiva pathoanalítica, recordando el neologismo schottiano, que iniciamos el estudio de una de las obras de Franz Kafka: El proceso. Esta obra tiene un carácter de universalidad que dispensa elogios o afirmaciones de reputación. Ella afirma y nos introduce en este extraño y extrañado mundo de la paranoia, no como un mundo exclusiva- mente de locos, sino como una posibilidad de todos nosotros.

\section{JOSEF K. Y ÉL (ELLOS)}

En la lectura de El proceso no tenemos tiempo para una reflexión creadora de una actividad representativa capaz de colocarnos en la exterioridad de la vida de Josef K. Somos sorprendidos o, más exactamente, lanzados repentinamente en un mundo extraño, de súbito, sin ninguna preparación. Al despertar, Josef K. tiene la nítida impresión, una certidumbre que se establece paso a paso, de que está siendo calumniado por alguien. La calumnia, rápidamente, muy rápidamente, comienza a efectivarse como una persecución con visos de legalidad. La visita sorpresa sufrida por Josef K. desencadena una experiencia de terror. La vivencia construida a partir del susto, de la falta de preparación y de la violenta intrusión, colocan a Josef $\mathrm{K}$. frente a una instancia desconocida. Más allá de la calumnia, de la violencia, de la agresión gratuita, la ausencia de precisión de ese alguien, ese él incógnito resulta una experiencia aterrorizante.

"Ellos" no pronuncian la acusación. $\mathrm{Su}$ indeterminación y la falta de referenciales son los elementos utilizados en la narrativa de Kafka para crear la atmósfera paranoica. Ese "él" que permanece igualmente indeterminado en el singular, pudiendo ser el sistema, la empresa, el Estado, cualquier persona, un amigo, un enemigo, es profunda- 
mente amenazador. Las preguntas que Josef K. se formula frente al grupo de desconocidos que lo interpela son significativas en la búsqueda de referenciarse en este extraño y extrañado mundo: ¿qué es esto?, ¿dónde estoy?, ¿en qué momento hice algo equivocado? Conjuntamente con otras preguntas, como: ¿quién soy yo?, ¿será que yo soy culpable? Josef $\mathrm{K}$. concentra su angustia en la búsqueda de ese "él" indeterminado, impersonal, frente a la instancia desconocida en la interrogación fundamental: ¿Quiénes son ellos?

Definitivamente el mundo está inseguro, alejado del abrigo cariñoso de los que pueden amarlo. Comienza a aparecer una preocupación extrema con "él", con la concomitante degradación de la situación de interlocución: todos pueden tornarse "él-ellos", desapareciendo así el alocutor. Surge un discurso en el que "tú", el sujeto a quien se dirige la palabra es virtualmente un "él", ocurriendo por esa razón la demolición de este alocutor, creciendo el "yo" y el "él".

En el libro de Kafka surge una proximidad con el discurso típicamente paranoico, en la medida en que el "yo" está expuesto a infinitas posibilidades de ser afectado y de sufrir ataques. A pesar de que en su discurso, Josef K., está sufriendo persecución, averiguaciones, presentaciones ante un jurado, en fin, el proceso, no podemos decir que Josef K. está, pura y simplemente, sufriendo de un delirio de persecución.
Él es un delirante en potencia. Hasta el final de la obra, el genio literario de Kafka mantiene en suspenso el objetivo del proceso, el nombre de los perseguidores y sus motivos. Finalmente, nada sabemos sobre la dimensión tercera, objeto del discurso de Josef K.

En el habla de nuestros pacientes paranoicos encontramos esa misma demolición del proceso de interlocución. Ellos hablan mucho de sí y del objeto de su discurso, generalmente "él", persona, cosa, objeto. El "tú" tiende a desaparecer, en la medida en que no siempre es considerado como digno de interlocución. Es bien conocida la actitud querellante en la paranoia y los riesgos de que este "tú" pase a ser considerado como un adversario. Diferenciándose de Josef K., los paranoicos consiguen especificar quiénes son "ellos", e incluso son capaces de construir un saber acerca de una serie de objetos. En otras palabras, los paranoicos construyen todo un mundo nuevo.

Nuestra interrogación acerca de ese "él" indeterminado nos conduce necesariamente a estudiar la denominada función de referenciación del lenguaje, es decir la posibilidad que el lenguaje tiene de enviarnos al mundo extralinguiístico, sea éste real, efectivo, material, imaginario, posible. Este mundo extralingüístico es mediatizado en la interlocución principalmente por la referencia a esa tercera persona, objeto, asunto, tema, cosa, excluida generalmente de la interlocución "yo"-“tú". 
Antes de continuar nuestro estudio, consideramos de interés realizar algunas precisiones acerca de la referencia y de los pronombres en acción en la interlocución.

\section{¿QUÉ ES “ÉL" EN EL LENGUAJE?:}

\section{LA CUESTIÓN DE LA REFERENCIA}

El concepto de referencia fue definido clásicamente por G. Frege, quien afirmó que el referente de una expresión es el objeto que ella designa. De esta forma, la concepción fregeana enfatiza la distinción existente entre sentido y referencia. El referente de una expresión está vinculado al objeto referido, mientras que el sentido de una expresión es la manera específica mediante la cual ella conceptualiza un objeto determinado. Frege se atiene esencialmente a la realización del análisis de enunciados y de proposiciones acerca de si las mismas son verdaderas o falsas. Con el advenimiento de los denominados filósofos del lenguaje común, en especial con Austin, se efectuó una profundización del estudio acerca de la relación entre la interlocución y los efectos pragmáticos de ésta, evidenciando la importancia de la referencia más allá del análisis fregeano. De esta manera, nuestro estudio no trata de demostrar sólo si el discurso es delirante o no, sino de verificar principalmente cómo el mundo se estructuró para aquel sujeto. Es decir que, mediante el análisis de los diversos componentes de la referencia, tenemos acceso no só- lo a las cosas que se constituyen para el sujeto, sino a los objetos que emergen frente al mismo y por consecuencia a su mundo.

Un análisis inspirado en Frege nos llevaría a elaboraciones de la denominada referencia absoluta, es decir, a interrogarnos sobre si cada lexema envía a un determinado objeto existente. En el caso de que nos interesemos por la realización no sólo absoluta de la referencia, sino también de la referencia relativa, somos remitidos a la articulación del lenguaje, al menos a otras dos dimensiones. La primera de ellas, es la que llamaremos referencia relativa al contexto (exofórica) o deíctica y la segunda es la denominada referencia relativa al cotexto (endofórica). Esta última es relativa no ya a la realidad extralingüística, sino al propio discurso. El cuadro $\mathrm{N}^{\mathrm{o}} 1$ busca evidenciar el análisis general de la referencia mostrando las principales implicaciones con relación a algunas dimensiones del lenguaje.

Considerando la cuestión específica presentada por el mundo de Josef K., así como la importancia de la dimensión "él", nos atendremos específicamente a la referencia de tipo exofórica, la cual es mediada por la deixis. La deixis involucra necesariamente tres componentes: la persona, el tiempo y el espacio. La definición del término deixis remite al dominio de la subjetividad del enunciado, evidenciándose así el origen subjetivo de la referenciación y el hecho de que, en el caso de las expresio- 


\section{Cuadro № 1 \\ Los tipos de referencia y sus elementos lingüísticos}

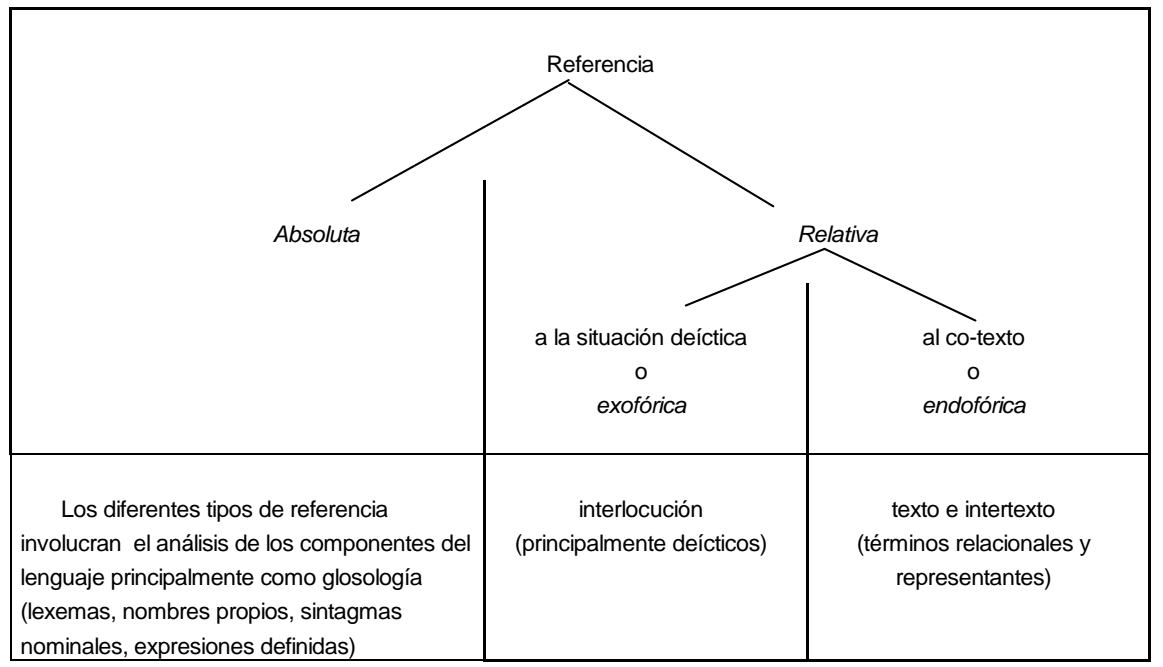

nes referenciales deícticas, el contexto del enunciado no es apenas externo $\mathrm{u}$ ontológico. Por el contrario, el contexto deíctico focaliza el aquí y ahora del locutor. Tal sistema de deixis basado en el locutor se denomina "sistema egocéntrico", noción elaborada a partir de la concepción de B. Russell de que los particulares egocéntricos (aquí, ahora, yo, esto) son palabras cuya denotación es relativa al locutor. La relación establecida entre deixis y referencia remite al hecho de que la referencia no es fija para algunos vocablos, ya que las coordenadas espacio-temporales son siempre relativas y se modifican en función de la perspectiva adoptada. El objeto denotado por las expresiones referenciales relativas se define dentro del contexto relacional del acto comunicativo.
Cada vez que la situación de enunciación se modifica, la referencia se verá igualmente modificada. Sin embargo, la alteración de la situación de enunciación no altera el significado deíctico que es constante y reside en la indicación de las relaciones con el contexto específico del acto discursivo. Tanto la semántica lógica como la semántica lingüística coinciden en afirmar que siendo el dominio (range) referencial de las expresiones referenciales determinado por el sentido que tienen en el idioma, su referencia efectiva depende de la variedad de los factores contextuales. $\mathrm{Pa}$ rret (1988), en un análisis preciso, mostró que la deixis constituye una especie de triángulo con sus diversos componentes, tal como intentamos explicitar en el cuadro $\mathrm{N}^{\circ} 2$. 
Cuadro № 2

El triángulo deíctico

\begin{tabular}{|c|c|c|c|c|c|c|c|c|c|c|}
\hline \multicolumn{3}{|r|}{ persona } & \multicolumn{4}{|c|}{ tiempo } & \multicolumn{4}{|c|}{ Espacio } \\
\hline yo & & no-yo & Ahora & & no-aho & & aquí & & no-ac & \\
\hline & tú & él nosotros, etc. & & antes & después & era una vez & & ahí & allí, allá & en otro lugar \\
\hline
\end{tabular}

El pronombre de tercera persona está situado, dentro del triángulo deíctico propuesto por Parret, en el campo del no-yo y consecuentemente, en oposición al campo del yo, paradigma del demostrativo indicial puro. El pronombre "yo" indica el locus de la enunciación. A partir de la organización egocéntrica formulada por este autor, creador de una teoría de la deixis en la que todo el dominio de las categorías deícticas se organiza en torno del "yo" y a la cual denominó "teoría egocéntrica de la deixis", es necesario establecer una distinción entre dos modalidades: deícticos puros e impuros. Los primeros: yo, tú, aquí, y ahora se refieren a los participantes de la interlocución, sin transmitir informaciones adicionales. Por otro lado, los deícticos impuros, cuyo paradigma es el pronombre personal "él", establecen diferenciaciones basadas en características y propiedades del referente que son independientes de las coordenadas espaciales y temporales en que se encuentran el locutor y el receptor de un determinado discurso.

En la concepción de Benveniste (1996), la clase de los pronombres de- nominados de "tercera persona", cuyo paradigma es "él", es una categoría perfectamente diferenciada de los pronombres "yo" y "tú", tanto por su función como por su naturaleza. En lo relativo a la función de los pronombres de tercera persona, ellos sustituyen un segmento del enunciado o la totalidad del mismo, constituyéndose en sustitutos abreviativos. De esta manera, el pronombre "él", al que Benveniste denomina "no-persona", representa el miembro no marcado de la correlación de persona, cuyos paradigmas son "yo" y "tú". A partir de esta definición, el autor afirma que la referencia de persona es una "referencia cero" que permanece fuera de la relación "yo"- "tú".

Lo que caracteriza a los pronombres de la tercera persona, sus rasgos distintivos -según el lingüista francés- son las siguientes propiedades: a) su capacidad de combinarse con cualquier referencia de objeto; b) el hecho de no ser reflexiva de la instancia del discurso; c) la posibilidad de involucrar un gran número de formas pronominales $\mathrm{y}$ demostrativas; y d) su incompatibilidad con términos referenciales tales como "aquî" y "ahora", que son expresio- 
nes deícticas paradigmáticas, ya que expresan las coordenadas determinadas por el locus espacio-temporal de la enunciación.

La comunicación impersonalizada privilegiará las posiciones relacionadas a los términos "él", "después", "allı̂, registrándose un aumento en la distancia entre yo (locutor) y el posible tú (alocutor), terminando por hacer desaparecer ese tú y tratando a todos como un él, un objeto exterior a la interlocución. De esta forma, el discurso paranoico acerca de él (ellos) mantiene distancia, cumple la máxima de no entrar en contacto, de no personalizar. Cuando esto sucede, eventualmente se transforma en actitud de querellante y se corre el riesgo de que seamos considerados como un "él" perseguidor. Pensamos que existe una estrecha relación entre la paranoia, y ese mundo impersonal y frío introducido por el pronombre "él", sin posibilidad de diálogo. La constancia del discurso con relación a una tercera persona nos lleva a interrogarnos acerca del estatuto específico de este denominado pronombre personal. Efectivamente, Benveniste nos enseña que ese deíctico no es exactamente un pronombre personal, sino más bien, un pronombre impersonal. Aunque no concordemos con que "él" es un pronombre impersonal, habremos de concordar que se dirige hacia la dirección de lo impersonal, de lo no-familiar, de lo indiferente, de lo ausente, de la nopersona, de las cosas.

\section{LA DEIXIS EN JOSEF K. Y EN EL DELIRIO DE PERSECUCIÓN}

En la historia de Josef K. señalamos la aparición de un mundo extremadamente inseguro. Este clima de inseguridad generalizada puede ser reencontrado en los tres planos del triángulo deíctico, al mismo tiempo en que ocurren irrupciones de conflictos en la realidad cotidiana de Josef K. Efectivamente, pensamos que ésta es una demostración del genio de Kafka: conseguir mantener un clima de indefinición, de terror, de aprensión posible y que se va realizando a lo largo del proceso, sin especificación final de los referentes. Claro que diversos personajes y causas son indicados a lo largo de la narrativa. Sin embargo, al concluir la lectura, tenemos la sensación de absurdo acerca del mundo vivido por el personaje de Kafka. Podríamos pensar que en un mundo donde nada es definido, todo se torna posible. Así, con relación a "él", a pesar del deslizamiento de objetos, finalmente nos sentimos inseguros en relación con el mundo efectivo que se forma: nos interrogamos acerca de lo indefinido, lo que siempre es potencialmente perturbador.

La indefinición desesperante no acontece sólo en relación con lo impersonal. Las personas, aun aquéllas más próximas, tienden a transformarse en alguien indiferente. Pensamos que el "tú", donde se sitúa la esencia del polo interlocutivo tiende a entrar en colapso, en la medida en que no existe una debi- 
da cualificación de lo que el sujeto ("él") tiene que decir. Todo lo que Josef $K$. dice acaba no siendo considerado, resultando en la transformación de los posibles "tú" en personas no dignas de interlocución. De esta manera, la tendencia general es el ataque al "tú", transformándolo en objeto de discurso, o sea en un "ellos" no-persona. Una dimensión esencial que se crea en estos estados próximos de la paranoia y similar a la misma, es la extrema soledad final del locutor. Soledad que se cierra más aun por la imposibilidad de confiar en sus interlocutores inmediatos. A cada nueva persona, todo retorna, ¿será que ese "tú" es bueno o malo? La indefinición es lógicamente anterior a cualquier diferenciación.

Vivir en un mundo de este tipo, fatalmente, nos hace pensar en que existe algo en el "yo" del sujeto que promueve la construcción de tanta indefinición. Para que pueda emerger el mundo humano, mundo de objetos plenos de significación, es necesaria la existencia de un "yo" que se constituya concomitantemente. No es sorprendente que el personaje de Kafka vuelva una y otra vez a interrogarse sobre el absurdo de ser tratado como un "yo" que no es él mismo. La interpelación radical sobre el propio principio de identidad resulta en la fórmula de la locura en relación con el polo locutivo: ser tomado por otro que el sujeto no es. Trátase de una interrogación en el verbo existencial "ser" que se refleja directamente en el deíctico "yo". La solución de Josef K. es la realización de una especie de lucha, mucho más un debatirse contra la intrusión que experimenta como proveniente del exterior. Vemos que es con mucho esfuerzo que Josef K. sostiene que es él mismo. Esta posición proyectiva, que no acepta ninguna predicación relacionada a sí mismo, lo coloca en una posición próxima a la paranoia, con la diferencia de que el "yo" en la paranoia acaba creciendo defensivamente.

De esta manera, en los tres planos deícticos nos encontramos en la dirección de una indefinición angustiante. Kafka consigue mantenernos en esta posición angustiante juntamente con Josef K. Pensamos que debido a esto, existe un íntimo parentesco entre esta posición y los momentos anteriores a la constitución de un delirio. Josef K. permanece en la inseguridad, mientras que la paranoia nos coloca casi siempre frente a alguien seguro de sí mismo, en extremo responsable, como diría Gagnepain, y convencido de la persecución, consigue llegar a nombrarlos, tal como ocurre en el delirio de persecución.

Recordemos un caso, entrevistado por un colega nuestro, para pensar en la cuestión de los deícticos en las psicosis. Se trata de una entrevista llevada a cabo en un servicio de emergencia y comandada por la urgencia del responder psiquiátrico. Podrá ser notada una cierta preocupación de nuestro colega 
por definir "aquello de lo que se trata", y consecuentemente la ausencia de casi cualquier silencio. Debido a la extensión de la entrevista, restringiremos nuestra observación al discurso del paciente y a las partes referentes a su delirio. Al serle preguntado cuándo se inició la persecución, el paciente comienza a dar informaciones precisas sobre quién lo persigue, relacionándolo al fatídico problema del padre.

- Psiquiatra, o A: ¿Cuándo falleció su padre?

- El paciente o P.: Falleció hace diez años, fue enero del ' 85.

A: $Y$ desde entonces...

P: La persecución anda suelta.

A: ¿Persecución por parte de quién?

$P$ : Por parte del hermano de mi madre.

A: ¿Del hermano de su madre?

P: Así es, yo sobreviví, ¿verdad?, gracias a Dios.

A: ¿Qué es lo que él ha hecho?

$P$ : Ha hecho mucho, de muchas maneras.

A: ¿Por ejemplo?

$\mathrm{P}$ : Boicoteándome en todo.

A: Pero, ¿qué hizo él?

P: Voy a hacer un negocio, él boicotea, manda arrestar, pegar, pegar con el cinto. No quiere pagar, ¿cierto?, quiebra realmente, hace el mayor desorden, rompe, que eso, que aquello.

A: No directamente.

$P$ : No directamente, él dice eso amenazándome. Sólo amenaza.

A: Dé un ejemplo concreto, bien objetivo, de lo que ya le sucedió.

P: Sucedió estando yo en el hospital, que me dieran una inyección en la vena; el corazón vino hasta aquí, casi me muero, hace dos días.

A: Yo digo así, del boicot de él.

$P$ : Entonces, antes de viajar por ahí, si yo parase, él paraba por causa de aquellas cuarenta y tres mil hectáreas, ¿verdad?, el re- curso para tomar en Maringá, en un avión particular. Sólo que no tiene nada que ver con él, con mi trabajo, porque el Dr. Nelson Correia de Brandão, que fue quien nos llamó allá en Mato Grosso, que es otro hermano de mi padre. Mi padre que es, que yo continúo, yo continúo en el cual, y el Dr. Elington, que es abogado de Maringá, nuestro, de la familia, que yo continúo pensando seriamente en comenzar una investigación aquí en Brasilia, de quien yo soy quien es. Yo, cuando fui agarrado para tener que parar, la primera cosa que yo pensé en hacer aquí, hay sirenas. Me preguntaron aquí fue: “¿de dónde tú vienes?". Yo me di vuelta, no, vamos a montar un escritorio, pero yo primero y me hicieron telefonearles, y yo creo que yo hice de tal forma que doce tipos me pegaron.

A pesar de que el discurso esté permeado por muchas interrupciones, imprecisiones, algunas frases incompletas y redundancias (típicas de una conversación espontánea), así como dificultades evidentes de traducción, queda en evidencia el hecho de que el señor P., nuestro paciente delirante no está viviendo en un mundo inseguro. Denominamos paranoia justamente a una construcción que busca liquidar la situación terrorífica de inseguridad y terror mediante la utilización del imaginario, desde un punto de vista narcisista. El delirio se construye como solución a esa gran interrogante que es lo indeterminado. Diferentemente de lo que sucede con el personaje de Kafka, vemos un sujeto lleno de certidumbre y ocupando el lugar del perseguido. Es decir, con relación a "ellos", ocurre la construcción de un mundo lleno de 
significaciones. Es bien conocido el hecho de que en la psicosis el mundo comienza a significar, a indicar causas.

La referencia se opera efectivamente en el delirio paranoico. Esta afirmación es tan verdadera que conseguimos reconstruir el mundo creado por el delirante. Diferentemente de la esquizofrenia, donde existe un ataque a la noción de significación, en el delirio tenemos conciencia de lo que el sujeto experimenta y describe, y por esta razón la psiquiatría clásica dio nombres a una serie de tipos de delirios diferentes basados en los diversos temas. Si la referencia opera en el delirio de persecución, esto no significa que estemos de acuerdo con el referente producido, sea éste real o imaginario. Una de las características esenciales del delirio con relación a la producción no delirante es la radical producción de referentes acerca de los cuales no estamos de acuerdo sobre su existencia real o imaginaria. El delirante está en discordancia acerca de los objetos del mundo y de las explicaciones que sobre ellos disponemos. El paranoico crea un mundo nuevo a partir de su punto de vista y de sus deseos, sin mayores consideraciones acerca de lo que los otros están pensando. El delirante reconstruye, tal como diría Freud.

Siendo el delirio un discurso acerca de las cosas, se hace evidente la importancia de la categoría deíctica "ellos". De esta forma, entendemos perfectamente que el tío de $\mathrm{P}$. es el perseguidor, el asesino de su padre, el usurpador de los bienes de la familia. Sin embargo, no estamos de acuerdo, ni sus familiares, de que esto realmente ocurrió. Diríamos que aquello que es pura posibilidad lógica, es tomado como realidad y verdad por el paranoico.

Se instala, principalmente, una oposición "yo-él". El "tú", si es que está inicialmente en la interlocución, es neutro y tiende a ser asimilado por las otras dos posiciones. En el transcurso de la interlocución paranoica, el "tú" tiende a tornarse un "yo" o un "él". La instancia del alocutario reconocido en su alteridad tiende a desaparecer en la paranoia. Cuando el paranoico consigue afirmar su discurso, su interlocutor es colocado, como mínimo, en una posición pasiva. Otras veces puede ocurrir la posibilidad de transformar al "tú" en discípulo, en seguidor. Es a partir de aquí que resulta clásicamente conocida la descualificación del otro en la interlocución. Cuando se produce una reacción por parte del alocutor, encontramos la posibilidad de la figura discursiva de la querella. Ésta es una de las posibilidades perturbadoras en el contacto con este tipo de pacientes. Cabe siempre la posibilidad de que el "tú", inicialmente neutro o inclusive amado, se transforme rápidamente en un perseguidor $y$, en consecuencia, alguien de quien se habla, pero no alguien a quien se dirija efectivamente la palabra.

La desaparición del "tú" instala una grave dificultad de comunicación. Sur- 
ge un sujeto presupuesto como grandioso, pero al mismo tiempo muy solitario. El paranoico no se queja por ser muy narcisista, pero siempre tiene la posibilidad de vivir la mayor de las soledades por la desaparición del polo "tú" de interlocución. Señalar la soledad es muchas veces uno de los pocos caminos que restan al terapeuta para crear un vínculo que no desemboque en una mixtura completa con el alocutor o en una oposición radical.

Entre el mundo inseguro de Josef K. $\mathrm{y}$ el mundo poblado por perseguidores designados por el delirante paranoico existen transiciones. En el cuadro buscamos mostrar la existencia de una definición a través del delirio que resuelve el clima de terror, inseguridad y angustia de Josef K., en las definiciones delirantes en el caso que presentamos.

\section{CONCLUSIÓN: LA PSICOSIS ES UN DISTURBIO RADICAL DE LA PERSONALIZACIÓN}

El presente estudio privilegió la investigación de la dimensión de la referencia deíctica, específicamente con relación a la categoría persona. Esta dimensión se encuentra perturbada no sólo en lo relativo al "yo", sino también en lo relativo a las dimensiones del no-yo del triángulo deíctico. Las dificultades relacionadas con la constitución de la realidad, representada en este estudio principalmente por el pronombre "él", se muestran articuladas con la subjetivación del sujeto. Entendemos que el estudio a través de los deícticos permitirá que en futuros trabajos se establezcan otras relaciones con la problemática del yo, desde el punto de vista psicoanalítico y con la comunicación lingüística, en especial dentro de la familia. Pensamos haber indicado, mediante el estudio de los deícticos y de la referencia, la posibilidad de esclarecer algunos aspectos acerca de la subjetivación y de la intersubjetivación en la psicosis.

\begin{tabular}{|l|l|l|l|}
\hline Josef K. & yo & tú & él \\
& $?$ & $?$ & $?$ \\
& interpelado & no confiable, & indefinido, en \\
& constantemente, & tiende a tornarse él & transformación \\
& sufriendo intrusiones, & & constante \\
& inseguro & & él \\
\hline Delirio de & yo & tú & Perseguidor \\
persecución & presupuesto como & tendencia a desaparecer & \\
& grandioso, narcisista & en la interlocución & \\
\hline
\end{tabular}


Martins

\section{REFERENCIAS}

Benveniste, E. (1966). Problèmes de linguistique générale. Paris: Galimard.

Ducrot, O. \& Todorov, T. (1970). Dictionnaire encyclopedique des sciences $d u$ langage. Paris: Seuil.

Frege, G. (1978). Lógica e filosofia da linguagem. São Paulo: Cultrix.

Parret, H. (1988). Enunciação e pragmática. Campinas: Unicamp.

Schotte, J. (1981). L'analyse du destin comme patho-analyse. Curso inédito. Université Louvain la-Neuve. 